\title{
Unsteady Hydromagnetic Flow of a Heat Absorbing Dusty Fluid Past a Permeable Vertical Plate with Ramped Temperature
}

\author{
M. Das ${ }^{1}$, B. K. Mahatha ${ }^{1}$, R. Nandkeolyar ${ }^{1 \dagger}$, B. K. Mandal ${ }^{2}$ and K. Saurabh ${ }^{2}$ \\ ${ }^{1}$ Department of Mathematics, School of Applied Sciences, KIIT University, Bhubaneswar-751024, India \\ ${ }^{2}$ Department of Mathematics, Vidya Vihar Institute of Technology, Purnea, India \\ † Corresponding Author Email: rajnandkeolyar@gmail.com
}

(Received April 23, 2013; accepted June 10, 2013)

\begin{abstract}
The unsteady flow and heat transfer of a viscous incompressible, electrically conducting dusty fluid past vertical plate under the influence of a transverse magnetic field is studied with a view to examine the combined effects of suction, heat absorption and ramped wall temperature. The temperature of the wall is assumed to have a temporarily ramped profile which goes on increasing up to a certain time limit and then becomes constant. To investigate the effect of rampedness in wall temperature, the solution for the flow past an isothermal wall is also obtained. The governing partial differential equations are solved using Laplace transformation technique in which the inversion is obtained numerically using Matlab. To validate the results of numerical inversion a comparison between the numerical and analytical values of fluid and particle temperatures and Nusselt number is also presented. The effects of pertinent flow parameters affecting the flow and heat transfer are investigated with the help of graphs and tables. It is found that the increase in suction, heat absorption and particle concentration contribute in thinning the thermal and momentum boundary layers and the velocity and temperature for both the fluid and particle phases are higher in the case of a flow past an isothermal plate than that of a flow past a plate with ramped temperature.
\end{abstract}

Keywords: Dusty fluid, Free convection, Heat absorption, Permeable wall, Ramped temperature.

\section{INTRODUCTION}

Heat generation/absorption effects on the free convective boundary layer flow of a viscous incompressible, electrically conducting fluid under the influence of a magnetic field are encountered in several industrial applications, such as underground disposal of radioactive waste materials, exothermic and/or endothermic chemical reactions, heat removal from nuclear fuel debris and dissociating flu-ids in packed-bed reactors etc. Due to this fact several researchers studied the effects of heat absorption by the fluid on the flow and heat transfer of a viscous, incompressible and electrically conducting fluid in the presence of a magnetic field. Chamkha (2000a) investigated magnetohdyrdynamic (MHD) boundary layer flow over an accelerating permeable surface in the presence of thermal radiation, thermal buoyancy force and heat generation or absorption. It was found that heat absorption coefficient reduces fluid temperature which resulted in decrease in the fluid velocity. The rate of heat transfer decreases as the heat absorption coefficient increases. Also heat absorption coefficient has tendency to reduce the rate of heat transfer. Ibrahim et al. (2008) discussed the effects of chemical reaction and radiation absorption on the unsteady MHD free convection flow past a semiinfinite vertical permeable moving plate with heat source and suction. The internal heat generation effects on the mixed convection boundary layer flow from a convectively heated vertical plate to a fluid are investigated by Makinde and Aziz (2011).

Wall porosity plays an important role on such flows by stabilizing the fluid flow and lowering the temperature within the flow field. This is also an effective technique to delay the boundary layer separation. Taking into account these facts, several researchers have studied suction/blowing effects on MHD flows past a flat plate. Chamkha (2004) discussed the unsteady hydromagnetic boundary layer flow of a viscous incompressible electrically conducting and heat absorbing fluid along a semiinfinite vertical permeable moving plate embedded in a uniform porous medium. Makinde (2005) studied the effects of wall porosity on the free convection flow with thermal radiation and mass transfer. Mbeledogu and Ogulu (2007) studied the heat and mass transfer on unsteady MHD natural convection flow of a rotating fluid past a vertical porous flat plate in the presence of radiative heat 
transfer. Afify (2009) discussed the MHD free convective heat and mass transfer flow over a stretching sheet in the presence of suction/injection with thermal diffusion and diffusion thermo effects.

The influence of dust particles on the flow of a viscous fluid has several important applications. The dust particles tend to retard the flow and to decrease the fluid temperature. Such flows are encountered in a wide variety of engineering problem such as nuclear reactor cooling, rain erosion, paint spraying, transport, waste water treatment, combustion, etc. The presence of solid particles such as ash or soot in combustion energy generators and their effect on performance of such devices led to studies of particulate suspension in electrically conducting fluid in the presence of magnetic field. Saffman (1962) initiated the study of dusty fluids and discussed the stability of the laminar flow of a dusty gas in which the dust particles are uniformly distributed Chamkha (2000b) investigated the unsteady laminar hydromagnetic fluid particle flow and heat transfer in channels and circular pipes considering two phase continuum models. The effects of Hall current on the Couette flow with heat transfer of a dusty conducting fluid in the presence of uniform suction/injection was studied by Attia (2005). Ghosh and Ghosh (2008) considered the problem of hydromagnetic rotating flow of a dusty fluid near a pulsating plate when the flow is generated in the fluid particle system due to velocity tooth pulses subjected on the plate in the presence of a transverse magnetic field. Makinde and Chinyoka (2010) investigated the unsteady fluid flow and heat transfer of a dusty fluid between two parallel plates with variable viscosity and thermal conductivity when the fluid is driven by a constant pressure gradient and subjected to a uniform external magnetic field applied perpendicular to the plates with Navier slip boundary condition. In all the above investigations a solution for the flow and heat transfer is obtained assuming the temperature at the interface of the plate as constant. However, there exist several problems of physical interest which may require non-uniform conditions. Gireesha et al. (2011) obtained the solution for the boundary layer flow and heat transfer of a dusty fluid over a stretching sheet with non-uniform heat source/sink. They considered two types of heating processes namely (i) prescribed surface temperature and, (ii) prescribed surface heat flux. Ramesh et al. (2012) analyzed the steady two-dimensional MHD flow of a dusty fluid near the stagnation point over a permeable stretching sheet with the effect of nonuniform source/sink. Recently, the effects of ramped surface temperature on the flow and heat transfer of a viscous, incompressible, and electrically conducting dusty fluid in the presence of a transverse magnetic field are studied by (Nandkeolyar et al. 2013 ; Nandkeolyar and Das 2013). They assumed that the surface temperature increases up to a specific time and then it becomes constant. They also compared the flow of dusty fluids through a wall having ramped temperature with that of a flow past an isothermal wall.
In the present paper, the unsteady flow and heat transfer of a viscous incompressible, and electrically conducting dusty fluid past a permeable flat plate under the influence of a transverse magnetic field is studied with a view to examine the combined effects of suction, heat absorption, and ramped wall temperature. The temperature of the wall is assumed to have a temporarily ramped profile which increases up to a certain time limit and then becomes constant. The governing partial differential equations are solved using Laplace transformation technique where the inversion is obtained numerically using a numerical technique suggested by Hollenbeck (1996). The effects of pertinent flow parameters affecting the flow and heat transfer are investigated with the help of graphs and tables.

\section{MATHEMATICAL FORMULA- TION}

We consider the unsteady flow and heat transfer of a viscous, incompressible, and electrically conducting dusty fluid past a permeable plate with ramped temperature under the influence of a transverse magnetic field. It is assumed that a free convective heat transfer is taking place and the fluid is heat absorbing. The co-ordinate system is chosen in such a way that $x$-axis is taken along the plate in the upward direction, $y$-axis is normal to the plate, and $z$-axis is perpendicular to $x y$-plane. The fluid is permeated by a uniform transverse magnetic field $B_{0}$ applied parallel to $y$-axis. The fluid motion is induced due to the impulsive movement of the plate as well as the free convection due to heating of the plate. Initially, at time $t^{\prime} \leq 0$, the fluid, dust particles, and the plate are at rest and at a uniform temperature $T_{\infty}^{\prime}$. At time $t^{\prime}>0$, the plate starts with uniform velocity $U_{0}$ and temperature of the plate is raised or lowered to $T_{\infty}^{\prime}+\left(T_{w}^{\prime}-T_{\infty}^{\prime}\right) t^{\prime} / t_{o}$ when $t^{\prime} \leq t_{0}$, and thereafter, for $t^{\prime}>t_{0}$, it is maintained at the uniform temperature $T_{w}^{\prime}$. At the surface of the wall there is suction/ injection with uniform velocity $v_{0}$, where $v_{0}>0$ corresponds to suction and $v_{0}<0$ corresponds to injection. Also it is assumed that the pores at the surface are very small so that there is no flow of dust particles through them. Since the plate is of infinite extent in $x$ and $z$ directions and is electrically non-conducting all physical quantities, except pressure, are functions of $y$ and $t^{\prime}$ only.

The fluid is a metallic liquid whose magnetic Reynolds number is very small and hence the induced magnetic field produced by the fluid motion is negligible in comparison to the applied one (Cramer and Pai 1973) so that the magnetic field $\mathbf{B} \equiv\left(0, B_{0}, 0\right)$. Also, no external electric field is applied, so the effect of polarization of magnetic field is negligible (Meyer (1958), i.e. $\mathbf{E} \equiv(0,0,0)$.

Under the above assumptions, the governing equations for the two phase flow and heat transfer model are:

$\frac{\partial \mathrm{u}^{\prime}}{\partial \mathrm{t}^{\prime}}-\mathrm{v}_{0} \frac{\partial \mathrm{u}^{\prime}}{\partial \mathrm{y}}=v \frac{\partial^{2} \mathrm{u}^{\prime}}{\partial \mathrm{y}^{2}}-\frac{\sigma \mathrm{B}_{0}^{2}}{\rho} \mathrm{u}^{\prime}+\frac{\mathrm{k}_{1} \mathrm{~N}_{0}}{\rho}\left(\mathrm{u}_{\mathrm{p}}^{\prime}-\mathrm{u}^{\prime}\right)$ 


$$
\begin{aligned}
& +\mathrm{g} \beta^{\prime}\left(\mathrm{T}^{\prime}-\mathrm{T}_{\infty}^{\prime}\right) \\
& \frac{\partial u_{p}^{\prime}}{\partial t^{\prime}}=\frac{k_{1}}{m}\left(u^{\prime}-u_{p}^{\prime}\right) \\
& \frac{\partial T^{\prime}}{\partial t^{\prime}}-v_{0} \frac{\partial T^{\prime}}{\partial y}=\frac{k}{\rho c_{p}} \frac{\partial^{2} T^{\prime}}{\partial y^{2}}+\frac{\rho_{p} c_{s}}{\rho c_{p} \gamma_{T}}\left(T_{p}^{\prime}-T^{\prime}\right) \\
& -\frac{Q_{0}}{\rho c_{p}}\left(T^{\prime}-T_{\infty}^{\prime}\right) \\
& \frac{\partial T_{p}^{\prime}}{\partial t^{\prime}}=\frac{1}{\gamma_{T}}\left(T^{\prime}-T_{p}^{\prime}\right)
\end{aligned}
$$

Where $u^{\prime}$ is fluid velocity in $x$ direction, $u_{p}^{\prime}$ is particle velocity in $x$ direction, $T^{\prime}$ is fluid temperature, $T_{p}^{\prime}$ is particle temperature, $T_{\infty}^{\prime}$ is ambient temperature of the fluid, $g$ is acceleration due to gravity, $\beta^{\prime}$ is volumetric coefficient of thermal expansion, $v$ is kinematic coefficient of viscosity, $\sigma$ is electrical conductivity of the fluid, $\rho$ is density of the fluid, $\rho_{p}$ is density of the dust particles, $k$ is thermal conductivity, $k_{1}$ is Stokes' resistance coefficient, $N_{0}$ is number density of the dust particles which is assumed to be constant, $m$ is average mass of a dust particle, $c_{p}$ specific heat at constant pressure of the fluid, $c_{S}$ is specific heat capacity of the dust particles, $\gamma_{T}$ is temperature relaxation time, and $Q_{0}$ is the heat absorption coefficient of the fluid.

The initial and boundary conditions for the flow and heat transfer are:

$u^{\prime}=u_{p}^{\prime}=0, T^{\prime}=T_{p}^{\prime}=T_{\infty}^{\prime}$ for $y \geq 0$ and $t^{\prime} \leq 0$,

$u^{\prime}=U_{0}$ at $y=0$ for $t^{\prime}>0$,

$T^{\prime}=T_{\infty}^{\prime}+\frac{\left(T_{w}^{\prime}-T_{\infty}^{\prime}\right) t^{\prime}}{t_{o}}$ at $y=0$ for $0<t^{\prime} \leq t_{0}$ $(5 \mathrm{c})$

$T^{\prime}=T_{w}^{\prime}$ at $y=0$ for $t^{\prime}>t_{0}$,

$u^{\prime} \rightarrow 0, T^{\prime} \rightarrow T_{\infty}^{\prime}$ as $y \rightarrow \infty$ for $t^{\prime}>0$.

Introducing the following dimensionless variables:

$$
\left.\begin{array}{c}
\eta=\frac{y}{U_{0} t_{0}}, u=\frac{u^{\prime}}{U_{0}}, u_{p}=\frac{u_{p}^{\prime}}{U_{0}}, t=\frac{t^{\prime}}{t_{0}}, \\
T=\frac{T^{\prime}-T_{\infty}^{\prime}}{T_{w}^{\prime}-T_{\infty}^{\prime}}, T_{p}=\frac{T_{p}^{\prime}-T_{\infty}^{\prime}}{T_{w}^{\prime}-T_{\infty}^{\prime}},
\end{array}\right\}
$$

the governing Eqs.(1) to (4) reduce the following non-dimensional from:

$$
\begin{aligned}
& \frac{\partial u}{\partial t}-S \frac{\partial u}{\partial \eta}=\frac{\partial^{2} u}{\partial \eta^{2}}-M u+R\left(u_{p}-u\right)+G r T, \\
& \frac{\partial u_{p}}{\partial t}=\frac{u-u_{p}}{\sigma_{1}} \\
& \frac{\partial T}{\partial t}-S \frac{\partial T}{\partial \eta}=\frac{1}{P r} \frac{\partial^{2} T}{\partial \eta^{2}}+\frac{2 R}{3 P r}\left(T_{p}-T\right)-\phi T, \\
& (9) \\
& \frac{\partial T_{p}}{\partial t}=\gamma\left(T-T_{p}\right),
\end{aligned}
$$

and the initial and boundary conditions (5),reduce to:

$$
\begin{aligned}
& u=u_{p}=0, T=T_{p}=0 \text { for } \eta \geq 0 \text { and } t \leq 0, \text { (11a) } \\
& u=1 \text { at } \eta=0 \text { for } t>0, \\
& T=t \text { at } \eta=0 \text { for } 0<t \leq 1, \\
& T=1 \text { at } \eta=0 \text { for } t>1, \\
& u \rightarrow 0, T \rightarrow 0 \text { as } \eta \rightarrow \infty \text { for } t>0,
\end{aligned}
$$

where

$$
\left.\begin{array}{c}
M=\frac{\sigma B_{0}^{2} v}{\rho U_{0}^{2}}, G r=\frac{g \beta^{\prime} v\left(T_{w}^{\prime}-T_{\infty}^{\prime}\right)}{U_{0}^{3}}, \operatorname{Pr}=\frac{\rho v c_{p}}{k}, \\
R=\frac{k_{1} N_{0} v}{\rho U_{0}^{2}}, \sigma_{1}=\frac{M U_{0}^{2}}{v k_{1}}, \gamma=\frac{v}{\gamma_{T} U_{0}^{2}}, S=\frac{v_{0}}{U_{0}}, \\
\phi=\frac{v Q_{0}}{\rho c_{p} U_{0}^{2}} .
\end{array}\right\}
$$

The non-dimensional parameters defined in Eq. (12) are, the heat absorption parameter $\phi$, the magnetic parameter $M$, the particle concentration parameter $R$, the Grashof number $G r$, the particle relaxation time parameter $\sigma_{1}$, the Prandtl number $\mathrm{Pr}$, suction parameter $S$, and the temperature relaxation time parameter $\gamma$.

According to the above non-dimensionalization process, the characteristic time $t_{0}$ can be defined as $t_{0}=\frac{v}{U_{0}^{2}}$.

\section{NUMERICAL SOLUTION}

The governing non-dimensional partial differential Eqs.(7) to (10) subject to the initial and boundary conditions prescribed in Eq.(11) can be solved using the Laplace transformation technique. Taking Laplace transformation of Eqs.(7) to (10) and solving the resulting differential equations subject to the transformed boundary conditions (11), we obtain:

$$
\begin{aligned}
& \bar{u}(\eta, s)=\frac{1}{s} e^{-\lambda_{2} \eta}+\frac{G r\left(1-e^{-s}\right)}{D_{1} s^{2}}\left(e^{-\lambda_{2} \eta}-e^{-\lambda_{1} \eta}\right), \\
& \bar{u}_{p}(\eta, s)=D_{2}\left[\frac{1}{s} e^{-\lambda_{2} \eta}+\frac{G r\left(1-e^{-s}\right)}{D_{1} s^{2}}\left(e^{-\lambda_{2} \eta}-\right.\right. \\
& \left.\left.e^{-\lambda_{1} \eta}\right)\right], \\
& \bar{T}(\eta, s)=\frac{\left(1-e^{-s}\right)}{s^{2}} e^{-\lambda_{1} \eta}, \\
& \bar{T}_{p}(\eta, s)=\frac{D_{3}\left(1-e^{-s}\right)}{s^{2}} e^{-\lambda_{1} \eta}
\end{aligned}
$$

where $\bar{u}, \bar{u}_{p}, \bar{T}$ and $\bar{T}_{p}$ are respectively, the Laplace transforms of $u, u_{p}, T$ and $T_{p}$ and are functions of $\eta$ and $s$. Here $s>0$ is the Laplace transform parameter and,

$$
\begin{aligned}
& a=\operatorname{Pr} S, b=\operatorname{Pr} \phi, c=\operatorname{Pr}+\frac{2 R}{3 \gamma}, \\
& d=b+\frac{a^{2}}{4} ; \lambda_{1}=\frac{a}{2}+\sqrt{c s+d}, \\
& \left.\lambda_{2}=\frac{s}{2}+\sqrt{\left(\frac{s^{2}}{4}+M+\left(1+R \sigma_{1}\right) s\right)},\right\} \\
& D_{1}=\lambda_{1}^{2}-S \lambda_{1}-M-\left(1+\sigma_{1}\right) s, \\
& D_{2}=\frac{1}{1+\sigma_{1} s} \text { and } D_{3}=\frac{\gamma}{s+\gamma} \text { ) }
\end{aligned}
$$

The problem now reduces to the problem of finding the inverse Laplace transformation of the functions $\bar{u}, \bar{u}_{p}, \bar{T}$ and $\bar{T}_{p}$ given by (14) to (17), respectively. To invert the functions defined in (14) to (17) a numerical algorithm is used as suggested by Hollenbeck (Hollenbeck 1996). This algorithm is a modified form of the De Hoog et al.( 1982) algorithm which takes care of the time vector which is split in segments of equal magnitude which are inverted individually to give better overall accuracy. In the present paper an accuracy of up to $10^{-8}$ decimal places is maintained. To verify the numerical results obtained from this modified algorithm we have also obtained the exact inversion of the functions $\bar{T}$ and $\bar{T}_{p}$ 
The exact solution for the fluid and particle temperatures may be obtained as:

$$
\begin{aligned}
& T(\eta, t)=e^{-0.5 a \eta}\left[P_{1}(\eta, t)-H(t-1) P_{1}(\eta, t-1)\right] \\
& T_{p}(\eta, t) e^{-0.5 a \eta}\left[P_{2}(\eta, t)-H(t-1) P_{2}(\eta, t-1)\right]
\end{aligned}
$$

where

$$
P_{1}(\eta, t)=\left(\frac{t}{2}+\frac{\eta c}{4 \sqrt{d}}\right) e^{\eta \sqrt{d}} \operatorname{erfc}\left(t_{1}\right)
$$$$
+\left(\frac{t}{2}-\frac{\eta c}{4 \sqrt{d}}\right) e^{-\eta \sqrt{d}} \operatorname{erfc}\left(t_{2}\right),
$$

$P_{2}(\eta, t)=\left(\frac{\gamma t-1}{2 \gamma}+\frac{\eta c}{4 \sqrt{d}}\right) e^{\eta \sqrt{d}} \operatorname{erfc}\left(t_{1}\right)$

$+\left(\frac{\gamma t-1}{2 \gamma}-\frac{\eta c}{4 \sqrt{d}}\right) e^{-\eta \sqrt{d}} \operatorname{erfc}\left(t_{2}\right)+$

$\frac{e^{-\gamma t}}{2 \gamma}\left[e^{\eta \sqrt{d-c \gamma}} \operatorname{erfc}\left(t_{3}\right)+e^{-\eta \sqrt{d-c \gamma}} \operatorname{erfc}\left(t_{4}\right)\right]$

$t_{1}, t_{2}= \pm \sqrt{\frac{d t}{c}}+\frac{\eta}{2} \sqrt{\frac{c}{t}} ; t_{3}, t_{4}= \pm \sqrt{\left(\frac{d-\gamma c}{c}\right) t}+\frac{\eta}{2} \sqrt{\frac{c}{t}}$

and the Nusselt number, which is a measure of rate of heat transfer at the plate, has the exact value:

$N u=-\left(\frac{\partial T}{\partial \eta}\right)_{\eta=0}=-F(t)+H(t-1) F(t-1)$

Where,

$$
F(t)=-\frac{a t}{2}-\left(\frac{c+2 d t}{2 \sqrt{d}}\right) \operatorname{erf}\left(\sqrt{\frac{d t}{c}}\right)-\sqrt{\frac{c t}{\pi}} e^{-\frac{d t}{c}} .
$$

The other physical quantity of engineering interest is the skin friction which may be obtain numerically using Matlab.

\section{SOLUTION OF THE PROBLEM IN CASE OF ISOTHERMAL PLATE}

To highlight the effects of rampedness in wall temperature it is worthwhile to compare the results obtained in this case with the results of a flow past an Isothermal plate. Keeping in view this fact the governing Eqs.(14) to (17) are subjected to Laplace transformation and the resulting equations are solved subject to isothermal boundary condition and we obtain:

$$
\begin{aligned}
& \bar{u}(\eta, s)=\frac{1}{s} e^{-\lambda_{2} \eta}+\frac{G r}{D_{1} s}\left(e^{-\lambda_{2} \eta}-e^{-\lambda_{1} \eta}\right) \\
& \bar{u}_{p}(\eta, s)=D_{2}\left[\frac{1}{s} e^{-\lambda_{2} \eta}+\frac{G r}{D_{1} s}\left(e^{-\lambda_{2} \eta}-e^{-\lambda_{1} \eta}\right)\right],(25) \\
& \bar{T}(\eta, s)=\frac{1}{s} e^{-\lambda_{1} \eta} \\
& \bar{T}_{p}(\eta, s)=\frac{D_{3}}{s} e^{-\lambda_{1} \eta}
\end{aligned}
$$

Again the inversions to obtain $u, u_{p}, T$ and $T_{p}$ are carried out numerically and for comparison of our numerical results the exact value of fluid and particle temperatures are obtained as:

$T(\eta, t)=e^{-0.5 a \eta} P_{3}(\eta, t)$

(28)

$$
\begin{aligned}
& T_{p}(\eta, t)=e^{-0.5 a \eta} P_{4}(\eta, t),(29) \\
& \text { where } \\
& P_{3}(\eta, t)=\frac{1}{2}\left[e^{\eta \sqrt{d}} \operatorname{erfc}\left(t_{1}\right)+e^{-\eta \sqrt{d}} \operatorname{erfc}\left(t_{2}\right)\right],(30) \\
& P_{4}(\eta, t)=\frac{1}{2}\left[e^{\eta \sqrt{d}} \operatorname{erfc}\left(t_{1}\right)+e^{-\eta \sqrt{d}} \operatorname{erfc}\left(t_{2}\right)\right] \\
& -\frac{e^{-\gamma t}}{2}\left[e^{\eta \sqrt{d-c \gamma}} \operatorname{erfc}\left(t_{3}\right)+e^{-\eta \sqrt{d-c \gamma}} \operatorname{erfc}\left(t_{4}\right)\right],
\end{aligned}
$$

The exact value of Nusselt number in case of a flow past an isothermal plate is obtained as:

$N u_{i}=\frac{a t}{2}-\sqrt{d} \operatorname{erf}\left(\sqrt{\frac{d t}{c}}\right)+\sqrt{\frac{c t}{\pi}} e^{-\frac{d t}{c}}$.

Skin friction, for the case of isothermal plate, may also be obtained numerically using Matlab.

\section{RESULTS AND DISCUSSION}

The effects of permeability of the wall, heat absorption and ramped wall temperature are studied on the unsteady flow of a viscous, incompressible, and electrically conducting dusty fluid in the presence of a transverse magnetic field. The governing partial differential equations are solved using Laplace transformation technique where the inversion is obtained numerically using Matlab. To validate the results obtained from numerical inversion the values of fluid and particle temperatures and Nusselt numbers, for both ramped temperature and isothermal plates, are compared with the values obtained analytically. The comparison shows an excellent agreement with the analytical results.

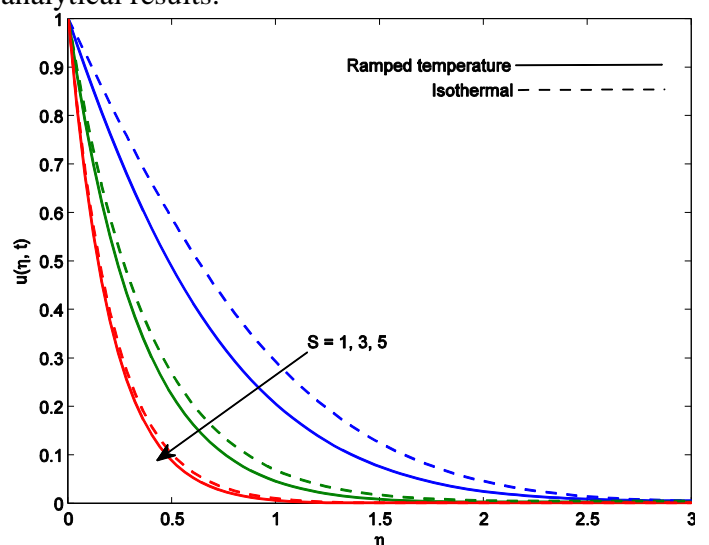

(a)

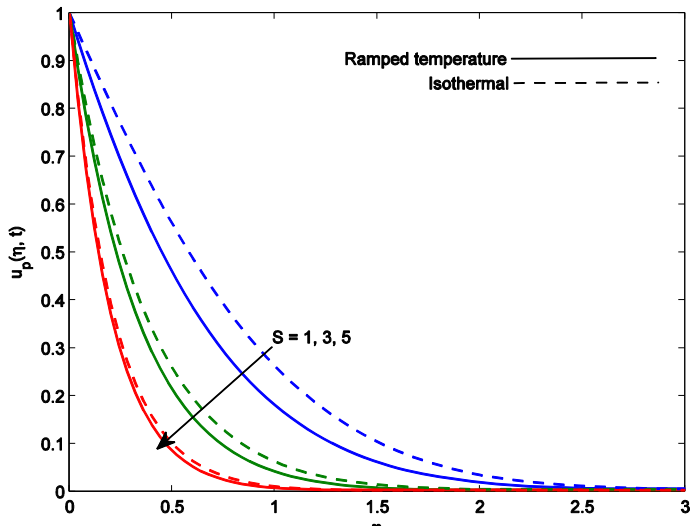

(b)

Fig. 1. Effect of $S$ on (a) $u(\eta, t)$ and (b) $u_{p}(\eta, t)$ when $t=0.7, \phi=1, R=0.1, P r=0.71$,

$$
M=1 \text {, and } G r=2 \text {. }
$$

Figures 1 and 2 shows the effects of suction parameter $S$ on the flow and heat transfer for both ramped temperature and isothermal plates. The suction parameter $S$ measures the suction velocity from the pores of the plate. It is found that an increase in suction through the pores of the plate 
causes a decrease in the fluid and particle velocities as well as fluid and particle temperature for both ramped temperature and isothermal plates. The decrease in fluid velocity is due to the acceleration of the fluid towards the plate and the decrease in temperature is due to the removal of heat with fluid moving out from the pores of the plate. The thickness of both the momentum and thermal boundary layers decrease with an increase in suction velocity and the velocity in case of an isothermal plate is more than that of a ramped temperature plate.

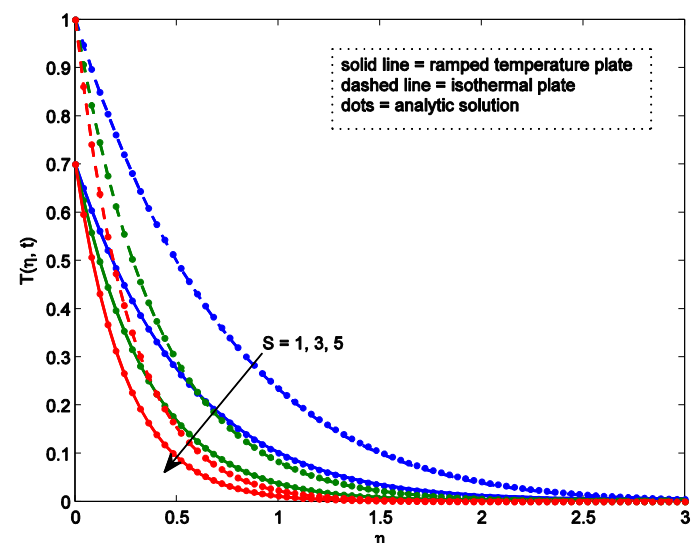

(a)

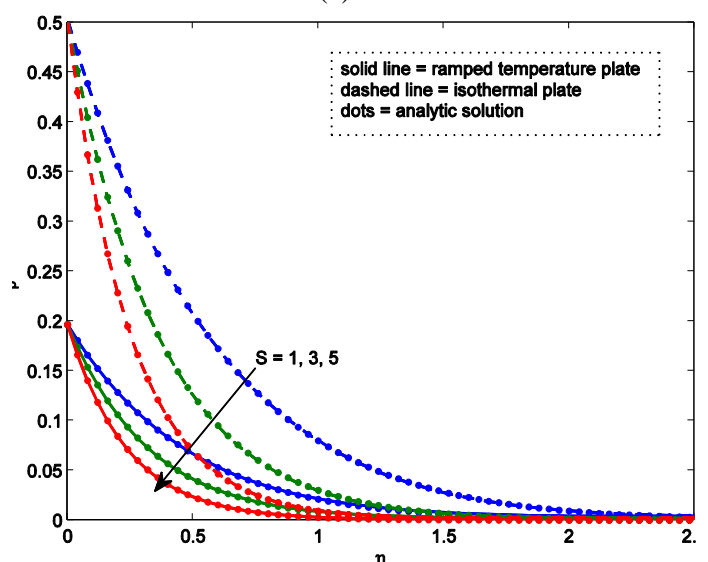

(b)

Fig. 2. Effect of $S$ on $T(\eta, t)$ and $T_{p}(\eta, t)$ when $t=0.7, \phi=1, R=0.1$, and $P r=0.71$.

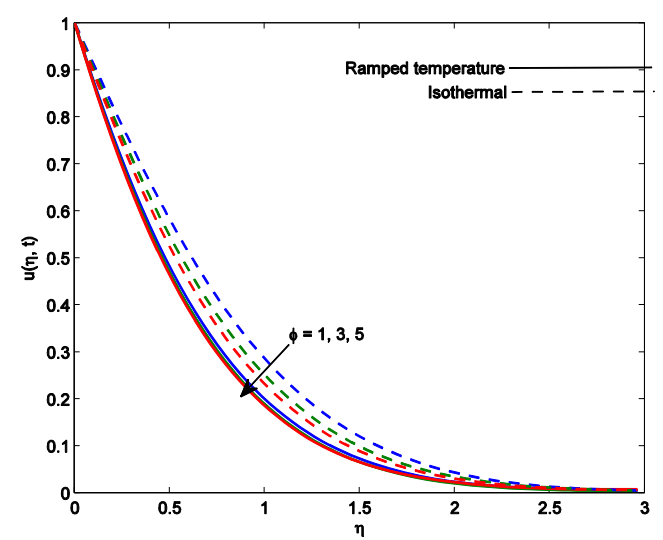

(a)

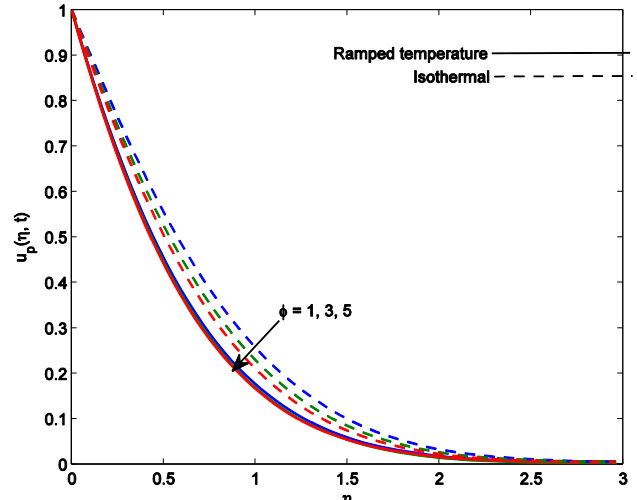

(b)

Fig. 3. Effect of $\phi$ on $u(\eta, t)$ and $u_{p}(\eta, t)$ when $t=0.7, S=1, R=0.1, P r=0.71, M=1$, and $G r=2$.

Figures 3 and 4 demonstrate the effects of heat absorption parameter $\phi$ on the flow and heat transfer for the fluid and particle phases for both ramped temperature and isothermal plates. The heat absorption parameter $\phi$ measures the amount of heat flux absorbed by the fluid particles. It is shown that the velocity and temperature are decreased by an increase in the heat absorption by the fluid. The central reason behind this effect is that the heat absorption causes a decrease in the kinetic energy as well as thermal energy of the fluid. The momentum and thermal boundary layers get thinner in case of heat absorbing fluids.

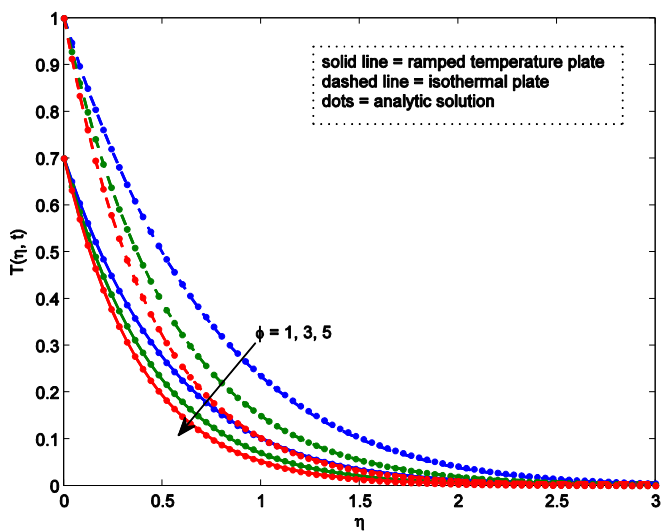

(a)

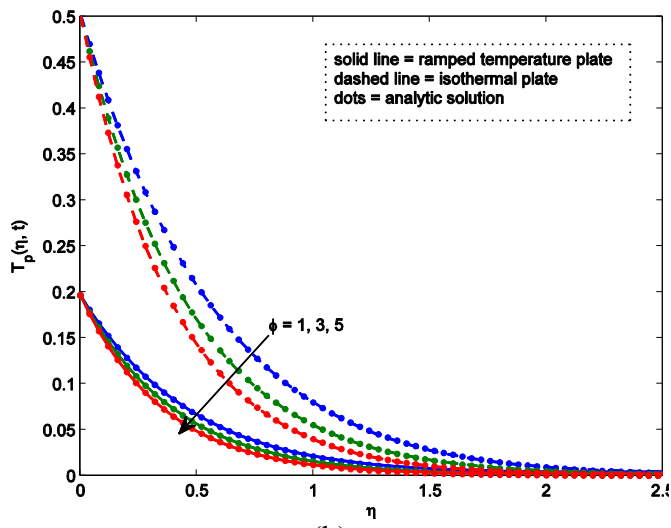

(b)

Fig. 4. Effect of $\phi$ on $T(\eta, t)$ and $T_{p}(\eta, t)$ when $t=0.7, S=1, R=0.1$, and $P r=0.71$. 
The effects of particle concentration parameter $R$ which quantifies the presence of dust particles in the flow field is exhibited in Figs. 5 and 6. It is revealed that the increase in dust particles in the flow field has a retarding influence on the fluid velocity and a decreasing effect on fluid temperature. It is due to the fact that presence of dust particles causes a resistive force in the fluid which in turn decreases the fluid velocity. Also the dust particles tend to absorb the heat from the fluid particles and as a result a decrease in the fluid temperature is encountered. The presence of dust particles in the flow field tends to decrease the thickness of the momentum and thermal boundary layers both.

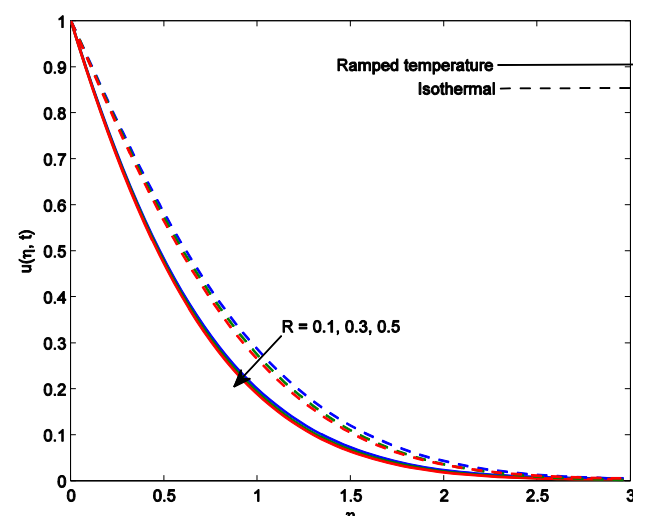

(a)

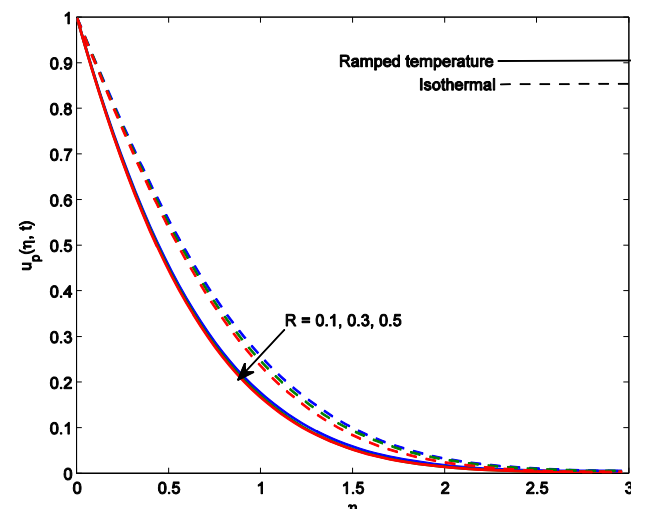

(b)

Fig. 5. Effect of $R$ on $u(\eta, t)$ and $u_{p}(\eta, t)$ when $t=0.7, S=1, \phi=1, \operatorname{Pr}=0.71, M=1$, and $G r=2$.

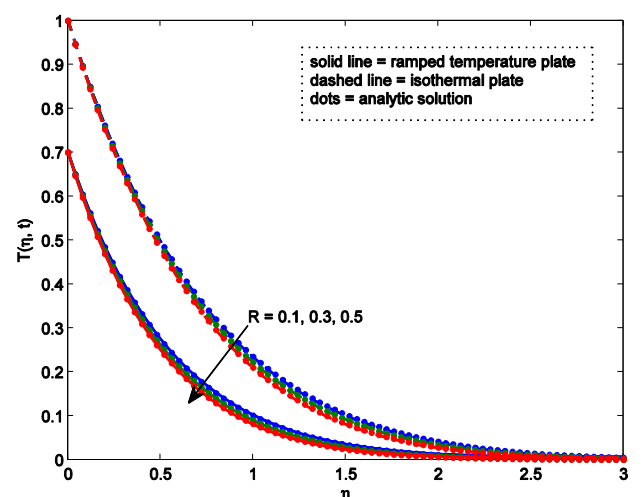

(a)

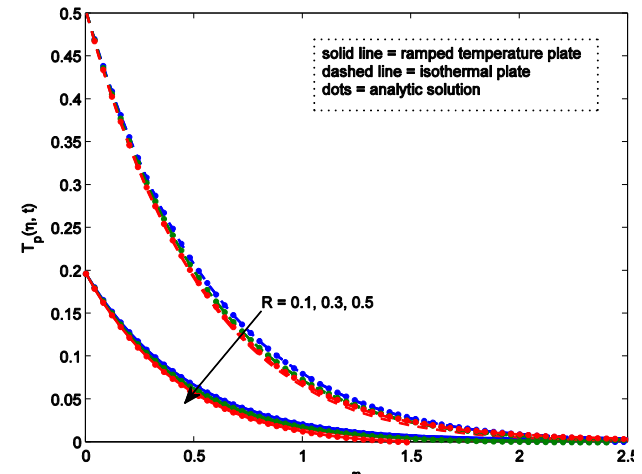

(b)

Fig. 6. Effect of $R$ on

$T(\eta, t)$ and $T_{p}(\eta, t)$ when $t=0.7, S=1, \phi=$ 1, and $P r=0.71$.

The effects of suction, heat absorption, and particle concentration on the skin friction $\tau$, for both ramped temperature and isothermal plates, are presented in Table 1. It is observed that skin friction, in both the cases, decreases with an increase in suction velocity, heat absorption, and particle concentration. Table 2 demonstrate the effects of suction, heat absorption, and particle concentration on the Nusselt number $N u$ which measures the rate of heat transfer at the surface of the plate. It is found that the heat transfer at the plate is increased by an increase in the suction velocity, heat absorption, and particle concentration.

Table 1 Skin friction when $\operatorname{Pr}=0.71, t=$ 0. 7, $\gamma=1, M=1, G r=2$, and $\sigma_{1}=0.1$.

\begin{tabular}{|l|l|l|l|l|}
\hline $\boldsymbol{S}$ & $\boldsymbol{\phi}$ & $\boldsymbol{R}$ & $\begin{array}{c}-\boldsymbol{\tau} \\
\text { (Ramped) }\end{array}$ & $\begin{array}{c}-\boldsymbol{\tau} \\
\text { (Isothermal) }\end{array}$ \\
\hline 1 & 1 & 0.1 & 1.16521943 & 0.79741994 \\
\hline 3 & - & - & 1.27305175 & 1.03949025 \\
\hline 5 & - & - & 1.32531926 & 1.15403752 \\
\hline 1 & 1 & 0.1 & 1.16521943 & 0.79741994 \\
\hline- & 3 & - & 1.25681601 & 0.94452064 \\
\hline- & 5 & - & 1.32491734 & 1.04742288 \\
\hline 1 & 1 & 0.1 & 1.16521943 & 0.79741994 \\
\hline- & - & 0.3 & 1.16828949 & 0.80784028 \\
\hline- & - & 0.5 & 1.17128472 & 0.81790346 \\
\hline
\end{tabular}

\section{CONCLUSION}

The unsteady flow of a viscous, incompressible, and electrically conducting dusty fluid in the presence of a transverse magnetic field is studied with a view to highlight the effects of porosity, heat absorption and ramped temperature of the wall. The significant findings of the study are presented below:

- The effect of suction velocity, heat absorption, 
and particle concentration is to decrease the thickness of the momentum boundary layer.

- The increase in suction velocity, heat absorption and particle concentration contribute in thinning the thermal boundary layer.
- The velocity and temperature for both the fluid and particle phases are higher in the case of a flow past an isothermal plate than that of a flow past a plate with ramped temperature.

Table 2 Nusselt number when $\operatorname{Pr}=0.71, t=0.7, \gamma=1$.

\begin{tabular}{|c|l|l|c|c|c|c|}
\hline $\boldsymbol{S}$ & $\boldsymbol{\phi}$ & $\boldsymbol{R}$ & $\begin{array}{c}\boldsymbol{N u} \text { (Analytic) } \\
\text { (Ramped) }\end{array}$ & $\begin{array}{c}\boldsymbol{N u} \text { (Numerical) } \\
\text { (Ramped) }\end{array}$ & $\begin{array}{c}\boldsymbol{N} \boldsymbol{u}_{\boldsymbol{i}} \text { (Analytic) } \\
\text { (Isothermal) }\end{array}$ & $\begin{array}{c}\boldsymbol{N} \boldsymbol{u}_{\boldsymbol{i}} \text { (Numerical) } \\
\text { (Isothermal) }\end{array}$ \\
\hline 1 & 1 & 0.1 & 1.27525314 & 1.27525314 & 1.34829508 & 1.34829508 \\
\hline 3 & - & - & 1.97658685 & 1.97658685 & 2.44307338 & 2.44307338 \\
\hline 5 & - & - & 2.81523700 & 2.81523700 & 3.74177824 & 3.74177824 \\
\hline 1 & 1 & 0.1 & 1.27525314 & 1.27525314 & 1.34829508 & 1.34829508 \\
\hline- & 3 & - & 1.55560744 & 1.55560744 & 1.86910369 & 1.86910370 \\
\hline- & 5 & - & 1.79277123 & 1.79277123 & 2.27466325 & 2.27466325 \\
\hline 1 & 1 & 0.1 & 1.27525314 & 1.27525314 & 1.34829508 & 1.34829508 \\
\hline- & - & 0.3 & 1.33077065 & 1.33077065 & 1.37273093 & 1.37273093 \\
\hline- & - & 0.5 & 1.38374310 & 1.38374310 & 1.39770273 & 1.39770273 \\
\hline
\end{tabular}

\section{ACKNOWLEDGEMENTS}

Authors are highly thankful to the reviewer for his valuable comments.

\section{REFERENCES}

Afify, A. A. (2009). Similarity solution in MHD: Effects of thermal diffusion and diffusion thermo on free convective heat and mass transfer over a stretching surface consideringsuction or injection. Commun. Nonlinear Sci.Numer. Simulat. 14, 2202-2214.

Attia, H. A. (2005). Hall effect on couette flow with heat transfer of a dusty conducting fluidin the presence of uniform suction and injec-tion. African J. Math. Phys. 2, 97-110.

Chamkha, A. J. (2000a). Thermal radiation and buoyancy effects on hydromagnetic flow over an accelerating permeable surface with heat source or sink. Int. J. Engng. Sci. 38, 16991712.

Chamkha, A. J. (2000b). Unsteady laminar hydromagnetic fluid-

particle flow and heat transfer in channels and circular pipes. Int. J. Heat Fluid Flow 21, 740-746.

Chamkha, A. J. (2004). Unsteady MHD convective heat and mass transfer past a semi-infinite vertical permeable moving plate with heat absorption. Int. J. Engng. Sci. 42, 217-230.

Cramer, K. and S. Pai (1973). Magnetofluiddynamics for Engineers and Applied physicists. McGraw Hill Book Company, New York.
Ghosh, S. and A. K. Ghosh (2008). On hydromagnetic flow of a dusty fluid near a pulsating plate. Comput. Appl. Math. 27, 130.

Gireesha, B. J., G. K. Ramesh, M. S. Abel, and C. S. Bagewadi (2011). Boundary layer flow and heat transfer of a dusty fluid flow over a stretching sheet with non-uniform heat source/sink. Int. J. Multiphase Flow 37, 977982.

Hollenbeck, K. (1996). INVLAP: A matlab function for numerical inversion of laplace transforms by the de hoog algorithm.

Hoog, F. R. D., J. H. Knight, and A. N. Stokes (1982). An improved method for numerical inversion of laplace transforms. SIAM J. Sci. Stat. Comput. 3, 357-366.

Ibrahim, F. S., A. M. Elaiw, and A. A. Bakr (2008). Effect of chemical reaction and radiation absorption on the un- steady MHD free convection flow past a semi-infinite vertical permeable moving plate with heat source and suction. Comm. Nonlin. Sci. Num. Simul. 13(6), 1056-1066.

Makinde, O. D. (2005). Free convection flow with thermal radiation and mass transfer past a moving vertical porous plate. Int. Commun. Heat Mass Transfer 32, 1411-1419.

Makinde, O. D. and A. Aziz (2011). Mixed convection from a convectively heated vertical plate to a fluid with internal heat generation. ASME J. Heat Transfer 133, 122501-1-6.

Makinde, O. D. and T. Chinyoka (2010). MHD transient flows and heat transfer of dusty fluid 
M. Das et al. / JAFM, Vol. 7, No. 3, pp. 485-492, 2014.

in a channel with variable physical properties and navier slip condition. Comp. Math. Appl. 60, 660-669.

Mbeledogu, I. U. and A. Ogulu (2007). Heat and mass transfer of an unsteady MHD natural convection flow of a rotating fluid past a vertical porous flat plate in the presence of radiative heat transfer. Heat Mass Transfer 50, 1902-1908.

Meyer, R. C. (1958). On reducing aerodynamic heat- transfer rates by magnetohydrodynamic techniques. J. Aero. Sci. 25, 561-572.

Nandkeolyar, R. and M. Das (2013). Unsteady MHD free convection flow of a heat absorbing dusty fluid past a flat plate with ramped wall temperature. Afr. Mat. Article in Press.
Nandkeolyar, R., G. S. Seth, O. D. Makinde, P. Sibanda, and M. S. Ansari (2013). Unsteady hydromagnetic natural convection flow of a dusty fluid past an impulsively moving vertical plate with ramped temperature in the presence of thermal radiation. ASME J. Appl. Mech. 80(6), 061003 1-9.

Ramesh, G. K., B. J. Gireesha, and C. S. Bagewadi (2012). MHD flow of a dusty fluid near the stagnation point over a permeable stretching sheet with non-uniform source/sink. Int. J. Heat Mass Transfer 55, 4900-4907.

Saffman, P. G. (1962). On the stability of laminar flow of a dusty gas. J. Fluid Mech. 13, 120134. 